\title{
LA INFLUENCIA DE LA REVOLUCión CULTURAL EN LAS MUJERES CHINAS
}

\author{
María Gómez y Patiño \\ mariagp@unizar.es \\ Universidad de Zaragoza
}

Recibido: 10-02-2013

Aceptado: 18-03-2013

\section{Resumen}

Si todos los procesos de transición política influyen en la ciudadanía en general, las mujeres suelen sufrir sus consecuencias doblemente: primero, a título individual, y segundo, como mujer. La influencia que la Revolución Cultural tuvo en China persiste en la mentalidad y en la vida de las mujeres del país asiático emergente par excellence. Este artículo presenta diez entrevistas personales realizadas in situ, a mujeres de distintos orígenes, edades, estatus social y nivel cultural, cuya vida se vio afectada por uno de los procesos políticos más fuertes que la historia universal ha recogido. El análisis y la interpretación de estas entrevistas ofrecen una perspectiva inédita de su visión del mundo, así como un testimonio oral de ese capítulo de la historia.

Palabras clave: Mujer, Revolución Cultural, China, Proceso de transición política.

\begin{abstract}
Political transition processes have an influence on the general citizenship, and women are the ones who suffer doubly its consequences: firstly, as individuals, and secondly, as women. The influence that the Cultural Revolution in China had over women persists today in the minds and life style of those ones who live in the emergent Asian country par excellence: China. This article presents ten personal interviews performed in situ, with Chinese women from different backgrounds, age, social status and cultural level, whose life was affected by one of the strongest political transition processes that world history has ever described. The analysis and interpretation of these personal interviews offer a unique perspective of their world view, as well as a historical oral testimony.
\end{abstract}

Keywords: Women, Cultural Revolution, China, political transition process. 


\section{Introducción}

Este artículo es resultado de una estancia en la Universidad de Pekín (Wanliu Campus of Peking University) en el verano del año 2008, coincidiendo con la celebración de los Juegos Olímpicos, hito histórico y mediático para la República Popular China. En ese momento el mundo fue testigo de un proceso de transición socio-económico de China. Pudo mostrar al todo el planeta su esplendor. A la sombra de este glamour mediático existe una realidad social distinta. La población china ha vivido varias transformaciones a lo largo del siglo XX, y resulta sumamente interesante poder recoger el testimonio directo de sus protagonistas.

Siendo conscientes de que todos los procesos de transición política influyen en la ciudadanía en general, las mujeres suelen ser más sensibles a estas influencias, con una doble vertiente: la primera, a título ciudadano, y la segunda, como mujer. Este artículo se centrará en esta segunda vertiente: la influencia de estos procesos de transición política en el destino de las mujeres (destino inseparable del masculino) que pretende mostrar algunas de las vivencias que estas mujeres, que habiendo ya vivido el proceso de la transición política de la Revolución Cultural (1966-1969), estaban siendo protagonistas y testigos de la transformación de la China del siglo XXI.

De forma generalizada se puede decir que hasta 1909 China había vivido bajo un sistema feudal, que paulatinamente se iría transformando, si bien arrastrando las consecuencias del régimen, lo que implica una serie de usos y costumbres que todavía están presentes en el imaginario chino. Fenómenos que de distinta forma afectaban a hombres y mujeres, desde la poligamia a la reducción de los pies femeninos.

Posteriormente China vivió las guerras mundiales, la primera (1914-1918) y la segunda (1939-1945), siendo 1939 cuando se produce la invasión japonesa, con la batalla de Changsha, de devastadoras consecuencias a todos los niveles. En 1966 tuvo lugar la Gran Revolución Cultural, teóricamente hasta el IX Congreso del Partido Comunista que tuvo lugar en 1969, pero realmente no concluyó definitivamente hasta la muerte de Mao Tse Tung en 1976. La influencia que estos hitos han tenido en la población china transciende su propia visión. Las mujeres chinas del siglo XX vivieron o pudieron sentir las huellas que estos cambios habían dejado, no sólo en ellas sino en sus ascendientes y descendientes. De todos estos procesos de transición política, la Revolución Cultural en China pervive en la mentalidad y en la vida de las mujeres del país asiático emergente par excellence.

Este artículo presenta y analiza diez entrevistas personales realizadas in situ, a mujeres de distintos orígenes, edades, estatus social y nivel cultural, cuya vida se vio afectada por uno de los procesos políticos más fuertes que la historia universal ha recogido: La Revolución Cultural. Su análisis y la interpretación de estas entrevistas ofrecen una perspectiva inédita de su visión del mundo, profundamente influenciadas por la transición política, que constituyen un magnífico un testimonio oral de ese periodo de la historia. 


\section{Objetivos}

Esta investigación se propone llevar a cabo una aproximación de la realidad social femenina, la china en este caso, que permitirá: 1) que aquellas mujeres que habiendo vivido un proceso de transición político (o varios), dan cuenta de su balance vital en la actualidad; y 2) su discurso permitirá observar su conformidad o disconformidad con su situación, relacionadas éstas con sus sueños y expectativas personales y profesionales, así como la influencia de la transición política en todos los casos.

Adentrarse en la lectura de este artículo exige un cambio de mentalidad difícil de afrontar, como lo fue avanzar en la investigación, dado que se trata de culturas tan distintas que en ocasiones surgen detalles y circunstancias vitales y discursivas difíciles de entender, para lo cual algunas lecturas complementarias pueden resultar de gran ayuda. De entre ellas, una de las más relevantes es la obra de Jung Chang (2004): Cisnes salvajes. Tres hijas de China, que relata episodios de difícil lectura por el horror que despiertan, pero que ayudan a comprender la realidad china del siglo XX. La descripción de la hambruna o sus consecuencias son difícilmente imaginables, como por ejemplo vender una hija por diez kilos de arroz. Éste era el valor de una niña, lo cual permite pensar la forma en que se iba configurando la identidad de una mujer y permite aventurar su autoestima.

Salvando las distancias y las diferencias culturales, las esencias y el proceso de construcción de la identidad femenina no difieren demasiado de una cultura a otra. En el caso de Occidente, o de España, más concretamente: "La mujer debía vivir y sobrevivir bajo las condiciones que le eran impuestas, donde su identidad resultaba minusvalorada, cercenada, o simplemente inexistente. La intracomunicación femenina estaba seriamente herida y su autoestima rara vez flotaba en la superficie social" (Gómez y Patiño, 2010:651). Esta relación interna ha ido teniendo expresiones y razones diferentes: culturales, políticas, económicas, demográficas, lo que permite la aproximación a la mujer china.

Los estereotipos están arraigados en nuestra sociedad (Bourdieu, 2000). Pensar en la mujer china, o su realidad, se convierte inevitablemente en algo extraño y lejano, exótico por tanto, que genera un halo de atracción por lo diferente. Tener la oportunidad de preguntar directamente al objeto de estudio (las mujeres chinas en China), diluyendo este halo de exotismo, es intelectualmente muy estimulante y permite jugar con esta aureola, manteniéndola o eliminándola. Todorov decía (2010:369): "No hay que dejarse engañar por el exotismo "geográfico" y creer que éste es el único ejemplo del encuentro con el otro, pero una vez entendido esto, se está obligado a escoger una forma de exotismo, preferida sobre las demás: la experiencia es necesariamente particular".

Ciertamente, conocer mejor al otro, incluso enmarcado en este exotismo real, permite conocerse mejor a uno mismo. En esta misma medida, conocer a la mujer china permitirá conocer mejor a la mujer occidental, a todas las mujeres, en general. 


\section{Problemas metodológicos y características de las mujeres entrevistadas}

Transcurrido el tiempo necesario para decantar y madurar el fruto de ellas, desde su realización, es preciso efectuar algunas aclaraciones que no serían necesarias en un contexto occidental, español o europeo, pero que resultan imprescindibles cuando se aborda un trabajo de este tipo en un contexto oriental, donde las diferencias culturales son tan relevantes como apasionantes.

El primer problema que hubo que afrontar y superar fue conseguir que diez mujeres chinas, de diferentes partes del país, pertenecientes a religiones y a clases sociales distintas, consintieran ser entrevistadas por una investigadora española (occidental y extranjera) con la mediación de una intérprete china. No puede olvidarse que China es un país bajo un régimen político (Partido Comunista Chino) donde la libertad de expresión es un valor humano ausente. Esto se dejó sentir en el transcurso de las entrevistas, que a pesar de ello, son más sinceras de lo esperable en tales circunstancias. Esa sola razón confiere a las entrevistas un valor testimonial inestimable. Por esta misma razón, a las entrevistadas no se les exigía que se identificaran con su nombre auténtico. Este dato no era relevante para la investigación y les permitiría una mayor sinceridad. Habida cuenta de estas circunstancias hubo que establecer un amplio margen en las características de las mujeres entrevistadas.

Dado que el requisito más importante era que hubieran pasado por un tránsito político, eso implicaba que 1950 era suficiente como año de nacimiento, si bien era deseable conseguir algunas entrevistadas de más edad y que enriqueciera este trabajo. Se trataba, sobre todo de conocer sus sueños, expectativas, deseos, pensamientos y sentimientos con relación a su propia vida, que había pasado por uno o varios tránsitos políticos, y que ahora permitía su revisión y su evaluación sedimentada.

Una de las ideas centrales de la investigación era que las entrevistas se realizaran a mujeres residentes en la República Popular China, porque la mujer que vive fuera, en el extranjero, ya ha estado en contacto con otras culturas e ideas y eso daría respuesta a un tipo de mujer distinta. Se trataba de obtener sus pensamientos y sentimientos con relación al desarrollo de su propia vida, dentro del escenario y del ámbito vital de China. Por tanto, se buscaba una mujer rural o urbana, educada o analfabeta, residente en la capital, en la costa o en el interior, que fuera famosa o anónima, rica o pobre, casada, viuda o divorciada, soltera o religiosa en una congregación. En este sentido, las palabras de Margaret Mead (1994:15) son muy reveladoras porque describen el objetivo de este tipo de trabajos de campo: "He pasado gran parte de mi existencia estudiando las vidas de otra gente, de pueblos lejanos, para que los norteamericanos pudieran comprenderse mejor". Sin querer ser pretenciosa, pensé como Margaret Mead, que si realizaba las entrevistas a mujeres tan lejanas, pertenecientes a ese exótico mundo, permitiría que las mujeres occidentales pudieran comprender mejor su situación, porque nuestra sensibilidad se va haciendo más fina a medida que conocemos otras realidades... 
En cuanto a la selección de la muestra, dadas las insalvables dificultades parcialmente descritas con anterioridad, la muestra $(n=10)$ es de tipo aleatoria, siguiendo un criterio de disponibilidad, y tratando de cumplir el perfil mínimo aquí descrito, tanto en requisitos personales como en representación geográfico-social.

En cuanto a la autoevaluación personal. Se suscitaba una pregunta: ¿Es capaz la mujer entrevistada de autoevaluar su vida, y hablar de un grado de satisfacción o de insatisfacción, de medir los riesgos y las amenazas que ha superado, y si la influencia política ha afectado a su personalidad y a su calidad de vida? Por ello, en la evaluación final se han tenido en cuenta también aspectos como la comunicación no verbal, los silencios, o lo no dicho, así como la evaluación deductiva de algunas de sus respuestas desde una valoración ajena y externa.

Sobre el cuestionario. Debido a las dificultades lingüísticas, culturales y socio-políticas debía ser muy concreto, sencillo y corto, permitiendo las respuestas abiertas, en función de la personalidad y de la libertad de la entrevistada. Se realizó el mismo cuestionario para todas las entrevistadas, pero con respuestas abiertas. Constaba de once preguntas en el que básicamente se preguntaba por su edad, por su infancia, por su adolescencia, por su juventud, por sus estudios, por su matrimonio, por sus hijos, por la influencia de sus mujeres mayores, por su lugar de residencia, por su trabajo, por lo que le gustaría hacer, y por aquello que le hubiera gustado hacer y no hizo.

En cuanto al tema central de este artículo: la influencia del proceso de transición política que vivieron, a ninguna de ellas se les preguntó directamente por ella, porque como es obvio, podrían haber negado tal influencia. De forma indirecta, ninguna de ellas dejó de hablar del tema, pues les había afectado a todas ellas sin excepción. Este tema es especialmente controvertido dado que la libertad de expresión en China está muy reducida por el sistema político y por el miedo instalado entre los ciudadanos. Una de las frases que las mujeres chinas me dijeron era que: "en China se dice sin decir". De alguna forma me quisieron decir que hay temas por los que no se debe preguntar. Quizá por esta razón no sorprenda que todas ellas hablan de la hambruna y de la Revolución Cultural, dos temas centrales, que constituyen la transición política en sentido estricto y por los que no habían sido preguntadas directamente.

Las preguntas formuladas para la investigación (Research Questions, $R Q=11$ ) fueron debidamente traducidas al chino de una forma adecuada. Básicamente el cuestionario consistió en estas preguntas:

RQ0 - ¿Cómo se llama?

(Puede dar el nombre que quiera. La identificación no es relevante para la investigación).

RQ1 - ¿Cuántos años tiene?

RQ2 - ¿Qué recuerdos tiene de su infancia?

(¿Fue una infancia feliz? ¿Recuerda acontecimientos concretos, tanto históricos como cotidianos?)

RQ3 - ¿Cómo fue su adolescencia? 
¿Disfrutó de su adolescencia plenamente o estuvo marcada por el trabajo, el sacrificio y el esfuerzo permanente?

RQ4 - ¿Cómo fue su juventud?

¿Pudo/quiso estudiar?

¿Aprendió alguna destreza/oficio que le permitiera trabajar?

¿Trabajó?

RQ5 - ¿Se casó?

¿Pudo/quiso elegir marido?

¿Resultó ser la pareja adecuada para usted?

¿Fue un buen marido?

¿Se sintió feliz como esposa?

RQ6 - ¿Tuvieron hijos?

¿Cuántos?

¿Les pudo ofrecer, como madre, lo que quiso para ellos?

¿Viven?

¿Fue su marido un buen padre?

¿Usted se sintió realizada como madre?

RQ7 - ¿Sigue viviendo en el lugar donde nació?

¿Le gustaría vivir en otro lugar?

¿Le gustaría viajar?

¿Le gustaría ver otros países?

RQ8 - ¿Trabajó siempre o durante un periodo?

¿Le gustaba el trabajo que hacía?

¿Le hubiera gustado hacer otro tipo de trabajo?

RQ9 - ¿Las mujeres de la familia (madre/abuela) han influenciado su vida?

¿Le han transmitido conocimientos femeninos, una manera de actuar y de ser?

RQ10 - ¿Qué le gustaría hacer que no haya hecho?

¿Existe mucha diferencia entre lo que usted soñaba de niña y lo que finalmente ha sido su vida? ¿Se siente satisfecha de su vida?

¿Vive ahora feliz su edad?

¿Ha encontrado la paz y la armonía consigo misma y con el mundo?

¿Los recuerdos de momentos pasados están presentes en su vida?

\section{Contextualización de las mujeres entrevistadas}

El contexto cultural y social del continente asiático en general es completamente distinto del europeo, por lo que exige un enfoque distinto. El hecho de que se haya hecho una pequeña incursión en cuestiones como la felicidad en la infelicidad, la satisfacción o la conformidad, al hablar con ellas se puede percibir que estos conceptos tienen distintos 
significados para ellas, por ello se focalizó en cuestiones tan concretas como la formación, el trabajo, el amor, el sexo, el matrimonio y los hijos.

\subsection{La cuestión femenina: formación, trabajo, amor, sexo, matrimonio e hijos}

No cabe duda que una aproximación al mundo de la formación y del trabajo, por la ineludible relación que tiene con la autonomía económica y la independencia personal, permite observar una parte sustancial de la realidad social, donde han de convivir hombres y mujeres, y donde las tradiciones culturales, filosóficas y religiosas han ido imponiendo distintas formas de relación. En este sentido, la cultura tradicional china, por milenaria y por distante de la europea requeriría un estudio previo difícil de abordar en este trabajo. Entre las corrientes filosóficopolítico-religiosas más importantes e influyentes en China, y de una forma conscientemente reduccionista, cabría destacar el confucionismo, el budismo y el taoísmo entre las más tradicionales y el maoísmo, entre las más recientes. Sin embargo, y con independencia de los diferentes momentos históricos, de sus prohibiciones y de sus imposiciones, podría decirse que todas las corrientes filosóficas chinas han estado caracterizadas por un marcado sentido patriarcal. Y ello a pesar de que en la ideología taoísta, el yin, como principio femenino, y el yang, como principio masculino, se han considerado iguales. De hecho, R.G.H. Siu (1968:2) afirma que: "la oposición, alternancia e interacción de estas dos fuerzas da lugar a todos los fenómenos del universo".

Si bien esta filosofía plantea la complementariedad de lo masculino y lo femenino, la idea patriarcal está muy por encima de este principio, lo cual no es nuevo y sí repetido de formas distintas. El sentido patriarcal está presente por tanto desde la formación al trabajo, y ello ha sido resaltado por gran parte de los autores que han abordado el tema. En este sentido, Castells y Subirats (2004:17-18), afirman que en China "las mujeres eran colocadas en la fábrica por los hombres que de ellas disponían y a quienes generalmente entregaban su salario. Una práctica que se ha reproducido en Asia del sudeste en las empresas electrónicas en el momento de la industrialización global". Esta práctica no sólo estaba instalada en Asia, por tanto en China, sino también en Europa, y por tanto en España.

De hecho, referido a la España del último tercio del siglo XX, Castilla del Pino (1971:91), afirmaba que: "son muy escasas aún las mujeres que gozan de autonomía económica, social y psicológica, como para homologarse en su situación a la situación de que goza el hombre usualmente".

Otra de las variables que permiten observar el grado de madurez de una sociedad es cada vez más frecuente el sistema de relaciones sexuales, donde a liberación sexual viene asociada a las sociedades más avanzadas, sociológica y tecnológicamente hablando. A este respecto, Castells y Subirats (2004:33) opinan que: "La liberación sexual de las mujeres, es decir, la capacidad de las mujeres para asumir y expresar su propia sexualidad, ha sido un tema recurrente de las revoluciones y los revolucionarios, tanto colectivos como individuales, de Alexandra Kollontai a Virginia Woolf'. Las mujeres chinas entrevistadas no han planteado en 
ningún momento la liberación sexual, y las relaciones sexuales se han producido siempre dentro del ámbito matrimonial, lo mismo que los hijos. En todo caso, en la realización de las entrevistas, el tema sexual e incluso amoroso fue algo que por razones culturales no se pudo abordar claramente. Las diferencias culturales que están presentes en cualquier aspecto social, lo son más aún en cuestiones como el amor, el matrimonio y los hijos. Obviamente, las diferencias culturales afectan tanto a hombres como a mujeres, y no se puede hablar de identidad femenina sin hablar de la masculina. En este sentido estricto, la filosofía china más aceptada y extendida contempla de una forma muy diferenciada lo femenino y lo masculino, el yin y el yan y su inextricable complementariedad.

En este caso, además de las diferencias culturales existentes también interviene el régimen político en el que China vivía hasta principios del siglo XX, cuyo estilo de vida estaba muy próximo al que se vivía en Europa en la Edad Media. Por ello es muy pertinente traer a colación la visión que sobre este aspecto tenía Georges Duby (1992) cuando opinaba que era imprescindible estudiar conjuntamente la evolución de la condición de cada uno de los dos sexos. En la Edad Media mejoraron tanto la condición femenina como la masculina, frente a épocas anteriores, si bien cabe preguntarse si la brecha existente entre los géneros se vio modificada realmente.

Grosso modo, con algunas excepciones, la educación y la socialización de las mujeres ha sido distinta y separada de los hombres a lo largo de la historia. No ha de extrañar que la educación en China estuviera segmentada porque en España, no ha sido hasta después de la Constitución (1978) cuando la educación ha comenzado a ser mixta, por lo que la identidad femenina y la masculina fueron moldeadas por separado, al igual que sus relaciones sociales. Las posibilidades de acceso a la educación superior para la mujer china fueron casi inexistentes no sólo por razones socio-económicas, sino también por razones culturales y por el sistema patriarcal imperante.

\subsection{La universalidad de la capacidad reproductiva de la mujer}

La capacidad reproductiva de la mujer es un principio universal al tiempo que una diferencia de género insalvable hasta la actualidad, en términos generales, lo cual ha condicionado secularmente su actividad. Tradicionalmente, la función social de la mujer se ha venido ejerciendo en el microespacio familiar y en sociedades tradicionales como la china, este fenómeno ha sido aún más evidente. En este sentido, Castilla del Pino (1971:34-5) afirma que: "la mujer que adquiera conciencia de la necesidad de su libertad debe hacer lo posible para evitar que en ella se den aquellas condiciones que a ella misma la inhibirían en el futuro, de esa aspiración”. Argumento éste que está estrechamente relacionado con las aspiraciones y los sueños de las mujeres chinas, y que es parte sustancial de los objetivos de la entrevista y de este trabajo.

La realidad de una sociedad tradicional como la china no ofrecía muchas posibilidades a la mujer salvo el de casarse, formar una familia y prestar un servicio a la sociedad mediante un 
trabajo, meramente funcional, mayoritariamente manual en fábricas o talleres del entorno. Ocasionalmente enseñaban a los niños más pequeños en las mismas escuelas en las que se habían formado, durante un tiempo, según los testimonios personales analizados para este trabajo.

La función de la maternidad aparece una un valor universal. La mujer china se muestra como una madre amorosa, que desea lo mejor para sus hijos, y eso favorece que se conserve el sistema familiar tradicional en el que ella ejerce un papel predominante. El sistema social se perpetúa y ella es co-protagonista junto a su marido de esa perpetuación social

Es sorprendente que también la forma matrimonial (por elección o sin ella), pasó por "conllevarse", como dice Castilla del Pino (1971:83), "esto es, a mantener las formas de una cotidianidad regularizada".

Las mujeres chinas no tuvieron mucho espacio público, al igual que las occidentales.

El hecho de que las mujeres no formasen parte del poder político oficial no las excluía de las tareas productivas. Eso es lo que afirma Cándida Martínez (1994), al exponer que las actividades realizadas por las mujeres eran básicas en el mantenimiento del sistema económico, ya que preparaban y arreglaban los instrumentos de trabajo, preparando recipientes, conservando los frutos, cuidándolos a lo largo de los meses; fabricando el vino y el aceite, confeccionando los vestidos, elaborando el alimento cotidiano. La precaria organización de la producción y el trabajo estaban basados en una falsa complementariedad, donde las mujeres, libres o esclavas, desempeñaban actividades no valoradas, pero fundamentales en el conjunto de la producción. Todavía hoy las mujeres son utilizadas como agente productivo, sin que se valore su actividad o se inscriba dentro de los distintos regímenes de seguridad tanto autónoma como por cuenta ajena, especialmente en áreas rurales.

Una vertiente particular de la mujer en esta actividad productora era la de constituir la mano de obra, mientras que la gestión y dirección del proceso estaba en manos de los varones. Era a través del vínculo marital o parental como se reproducía esta situación. Tanto ese vínculo como la posición de dominio venían reforzados por la posición pública y política de los varones.

En el seno del grupo doméstico, por ejemplo, había distribución de roles. Mientras que los hombres tenían a su cargo la actividad exterior, social y pública; las mujeres normalmente se encontraban confinadas en el interior, en esa habitación que era, en el corazón de la casa, como una matriz, y que no pocos autores han identificado con la cocina. No puede olvidarse que el lema $K-K-K$ (Kuche, Kinder, Kirche) (Cocina-Hijos-Iglesia) está todavía hoy vigente en muchas de las mentalidades demócrata-cristianas con lo que, producción, reproducción y religión son tres vocablos plenamente actuales. En esta interioridad reconocemos lo que era la función femenina esencial: la procreación, pero también el gobierno de los secretos más misteriosos de la vida, que afectan al nacimiento y a la muerte, ya que eran las mujeres las que procedían a lavar los cuerpos de los recién nacidos y, también, los cadáveres de los difuntos. El interior de la casa asimismo, se correspondía natural y metafóricamente con el cuerpo femenino. Finalmente, tanto trabajadoras como reproductoras de mano de obra o del cuerpo cívico, como grandes propietarias o pequeñas campesinas provincianas, las mujeres del pasado estuvieron privadas de la proyección política que les permitiera hacer valer sus intereses y 
derechos, (excepciones hechas de su pertenencia a una clase social alta). Su espacio era el doméstico. Es este dominio interior secular el que ha hecho que la identidad femenina se sienta más cómoda en lo íntimo, en las distancias cortas, e incluso en los ambientes donde los sentimientos y las emociones se manifiestan de forma privada.

Hablar y escuchar a estas mujeres me ha permitido entender mucho más de lo que han dicho verbalmente para las entrevistas. Su lenguaje no verbal, y su silencio en ocasiones, transmitía mucha más información que la verbalizada. En este sentido, como dice Margarita Rivière (2000:12): "He hablado con muchas mujeres, las he observado y sé de su irreversible determinación, porque las mujeres no sólo han comprendido que ellas también son responsables sino que quieren serlo, y algunas, las más lúcidas, saben que hoy el mundo está en sus manos".

En sus entrevistas parecían decir que vivieron tal como lo hicieron porque eran conscientes de que era su obligación, porque sabían que sus hijos y sus maridos dependían de ellas, al igual que la transmisión de la educación y de los valores personales y familiares.

\subsection{La percepción de la felicidad de la mujer}

El tema de la felicidad es tan extenso y profundo que no es abordable de una forma sumaria, pero se pueden presentar definiciones adecuados como la que ofrece Pardo (2002:7) en su Prólogo a Schopenhauer (2002): "aquel estado en el cual todos nuestros deseos estarían plena, inmediata y permanentemente satisfechos, y en el cual todo lo que queremos estaría completamente realizado". A lo que añade (ibid.:9) "reduzcamos nuestros deseos y aspiraciones hasta el mínimo, porque así minimizaremos las posibles frustraciones y las ocasiones de desconsuelo y desesperación". Las ideas son sencillas, pero su consecución no tanto, de forma que el individuo tiende a compensar su ausencia de otras formas. En este sentido, parece pertinente incorporar algunas reflexiones al respecto de la Felicidad en la infelicidad, título que corresponde a la obra de Odo Marquard. Sus textos tienen en común la defensa de lo imperfecto en el hombre: "la segunda mejor posibilidad, las soluciones vicarias, aquello que no lo es en absoluto. Lo absoluto -lo perfecto sin más, lo extraordinario es humanamente posible, porque los hombres son finitos. "Todo o nada" no es para ellos una divisa practicable: lo humano yace en el medio, lo verdadero es lo medio. Los hombres son así, deben y pueden hacer algo en vez de otra cosa, y lo hacen: cada hombre [...] se convierte en un homo compensator" (Marquard, 2006: 9). La idea del homo compensator es central, en especial en la valoración de los resultados y en las conclusiones, porque posiciona al individuo en un punto en el que compensará y equilibrará su situación. Este mismo autor (Ibid.:11) añade que: "Para los hombres no existe la felicidad sin sombras" [...] "la felicidad humana es, siempre, felicidad en la infelicidad". Como se verá en la valoración de los resultados, en muchos casos, la felicidad estriba en tener los medios para llevar una vida digna, y sobrevivir.

Mientras que Arthur Schopenhauer (2002) plantea las diferencias aristotélicas de lo que uno es, lo que uno tiene y lo que uno representa, para la mentalidad y la filosofía china ni siquiera lo plantea. La felicidad va unida a una cierta conformidad con la vida, lo que 
constituye una especial forma de espiritualidad, que en el caso de la cultura china está estrechamente unida a una corriente taoísta que, lejos de ser un problema, facilita enormemente la existencia, conforme a la vida que ha tocado vivir.

La felicidad, que no existe como absoluto, se asimila más bien a un bienestar temporal, parcial. En ese sentido, su sentido del bienestar era tan pequeño, demandaban tan poco a su vida, que realmente no necesitan apenas nada para conseguir un cierto bienestar pasajero. $\mathrm{Su}$ bienestar era tan efímero y sutil que se satisfacía fácilmente. Como decía Margarita Rivière (2000:243): "El bienestar no es algo solamente material sino algo sutil que enlaza con la actitud y la mirada ante la vida". En este sentido, las mujeres entrevistadas dejarán su impronta, fuertemente marcada por su actitud y su mirada personal.

Para cerrar este apartado sobre la felicidad, Carlos García Gual (2001:124), entre los textos escogidos de Epícuro cita el número cinco, que literalmente dice: "La felicidad y la dicha no la proporcionan ni la cantidad de riquezas ni la dignidad de nuestras ocupaciones ni ciertos cargos y poderes, sino la ausencia de sufrimiento, la mansedumbre de nuestras pasiones y la disposición del alma al delimitar lo que es por naturaleza”.

\section{Explotación de los resultados}

A la hora de analizar los resultados es necesario recordar algunas de las limitaciones encontradas para realizar las entrevistas, porque justifican en buena medida las circunstancias y dan valor a los hallazgos, dado que realizar las entrevistas resultó extremadamente complicado. Fueron múltiples las dificultades que tuvieron que ser superadas:

- La primera limitación fue la lingüística: ninguna de las entrevistadas hablaba español, ni inglés ni ningún otro idioma extranjero, por lo que hubo que contar con la ayuda de traductores, o mejor de intérpretes simultáneos, que al ser chinos, conferían una cierta sensación de confianza y seguridad a las entrevistadas. Además, la lengua china, al ser de carácter ideográfico, las respuestas no son siempre exactas. La precisión y la concisión resultan muy difíciles, no sólo por la naturaleza de la lengua, sino también por el carácter y la cultura de los ciudadanos chinos, y más aún de las cautelas de las mujeres chinas que, en una situación de escasa libertad de opinión, podían verse afectadas en su expresión verbal personal. Es necesario añadir además que dadas todas estas características, su expresión no verbal fue en ocasiones superior a la verbal, lo cual, si bien no se ha podido reflejar en sus respuestas concretas, sí ha aportado algún matiz a la interpretación de los datos.

- La segunda, la dificultad de la representatividad, dado que era prácticamente imposible abarcar toda la extensión del país. En el diseño de los puntos de muestreo, se pensó entrevistar a mujeres no sólo de Beijing, en cuya universidad hacía una estancia, sino también de la costa y del interior. Se llevaron a cabo por tanto en 6 ciudades distintas para conseguir una mayor representación socio-geográfica. Los puntos fueron: 1) Beijing; 2) Hafei; 3) Chanching; 4) 
Anjui; 5) Pingyao; y 6) Liaoching, es decir, puntos alejados entre ellos en ocasiones en 2.000 kilómetros. Todas ellas situadas en el centro-este y norte del país.

Las limitaciones y las dificultades fueron creciendo al tiempo que se reducían las posibilidades reales de la realización de las entrevistas. Finalmente, por todo ello, los resultados obtenidos tienen una validez estrictamente empírica, y puede que escasamente representativa, siendo lo más valioso de todo su valor testimonial a título personal.

Las entrevistadas eran, en su mayor parte, mujeres que no habían tenido una gran vida social, y mucho menos habían sido entrevistadas con fines académicos o científicos. Esto quiere decir que inicialmente mostraron un cierto rechazo o al menos mucha resistencia a someterse a realizar una entrevista. Lógicamente, el control del régimen político ejercido se hace sentir en todas ellas. Solamente el hecho de haber podido contar un buen equipo de entrevistadores, capaces de llevar a cabo las entrevistas, permitió llegar a resultados concretos. Lo cual no excluye que, a pesar de que el anonimato fue garantizado, en sus circunstancias y en su historia personal el miedo era muy entendible, por lo que no se forzaron las condiciones en ningún momento. Se llevaron a cabo de la forma más relajada y natural posible, en ocasiones en su propia vivienda, para conseguir que se sintieran más cómodas.

Con los datos obtenidos, se ha confeccionado un cuadro-resumen, en base a las diez mujeres entrevistadas y a sus respuestas:

Tabla 1. Resumen Cuestionario $(R Q=11)$

\begin{tabular}{|c|c|c|c|c|c|c|c|c|c|c|}
\hline Entrada $\mathbf{N}^{\mathbf{o}}$ & 1 & 2 & 3 & 4 & 5 & 6 & 7 & 8 & 9 & 10 \\
\hline Edad & 74 & 94 & 56 & 80 & 56 & 47 & 75 & 60 & 70 & 70 \\
\hline Infancia $^{1}$ & $\mathrm{~F}$ & $\mathrm{~F}$ & $\mathrm{~F}$ & $\mathrm{~F}$ & I & $\mathrm{R}$ & $\mathrm{F}$ & $\mathrm{F}$ & $\mathrm{F}$ & $\mathrm{F}$ \\
\hline Estudios $^{2}$ & S & $S$ & $\mathrm{U}$ & FP & $S$ & $S$ & SE & SE & S & $S$ \\
\hline Estado Civil $^{3}$ & $\mathrm{C}$ & $\mathrm{C}$ & $\mathrm{C}$ & $\mathrm{C}$ & $\mathrm{C}$ & $\mathrm{C}$ & $\mathrm{C}$ & $\mathrm{D}$ & $\mathrm{C}$ & $\mathrm{C}$ \\
\hline Elección marido & Sí & No & Sí & Sí & Sí & Sí & No & Sí & Sí & No \\
\hline $\mathbf{N}^{\circ}$ Hijos & 3 & 3 & 1 & 4 & 1 & 1 & 4 & 1 & 2 & 3 \\
\hline Buen Padre & Sí & Sí & Sí & Sí & Sí & Sí & Sí & Sí & Sí & Sí \\
\hline Buen Marido & Sí & Sí & $\mathrm{R}$ & Sí & No & Sí & Sí & No & Sí & Sí \\
\hline Trabajo & Sí & Sí & Sí & Sí & No & No & Sí & Sí & Sí & Sí \\
\hline Influencia Femenina & Sí & Sí & Sí & Sí & No & No & Sí & Sí & Sí & Sí \\
\hline Sueños $^{4}$ & NO & S.In & NO & Sí & S.In & S.In. & NO & S.In. & S.In. & Sí \\
\hline Aceptación Realdad & Sí & Sí & Sí & Sí & No & Sí & Sí & No & No & Sí \\
\hline
\end{tabular}

\footnotetext{
${ }^{1}$ Infancia: $\mathrm{F}=$ Feliz; I = Infeliz; $\mathrm{R}=$ Regular.

${ }^{2}$ Estudios: $\mathrm{S}=$ Secundarios; U = Universitarios; FP = Formación Profesional; $\mathrm{SE}=$ Sin Estudios.

${ }^{3}$ Estado Civil: C = Casada; D = Divorciada.

${ }^{4}$ Sueños: S. In. = Sueños incumplidos.
} 
Los hallazgos encontrados, más allá de los números, son cualitativamente muy clarificadores. Dado que han sido diez las mujeres entrevistadas, la cifra permite fácilmente establecer los porcentajes correspondientes y contemplar más sencillamente los resultados totales en términos porcentuales. De esta forma se puede afirmar que el $60 \%$ de las mujeres eran mayores de 70 años, lo cual, es muy significativo por sí mismo, por dos razones fundamentalmente: la primera es que la esperanza de vida de las mujeres en China es muy alto y la segunda es que si se tiene en cuenta que todas las entrevistadas sufrieron la hambruna y la Revolución Cultural, dos acontecimientos socio-histórico-políticos difíciles de ser superados, las entrevistadas lo hicieron y con buena salud.

La mayor parte de ellas afirmó que había vivido una infancia feliz. Sólo un $10 \%$ resultó infeliz, y $10 \%$ no del todo feliz, lo que permite pensar que la felicidad no está excluida de circunstancias material o económicamente poco afortunadas. El sistema chino de familia es muy protector y el núcleo familiar suministra grandes escenarios para el afecto y la protección. Los padres y los abuelos suelen ser buenos educadores al tiempo que afectuosos, lo cual hace que los niños no sientan grandes carencias materiales y en cambio, se sientan muy afortunados por el cuidado, la atención y el afecto que se les ofrece.

En lo relativo a la formación de las entrevistadas, su nivel formativo es muy diferente y varía en función de la clase social y del ámbito geográfico de nacimiento, siendo todas ellas mujeres ilustradas en el sentido de saber leer y escribir correctamente, lo cual en ideogramas chinos no es nada fácil. El $60 \%$ de ellas había cursado estudios secundarios; $10 \%$ poseían el equivalente a Formación Profesional, igual porcentaje que para los estudios universitarios, y el $20 \%$ restante no habían cursado estudios reglados, pero sabían leer y escribir, por lo tanto, en la muestra entrevistada, el analfabetismo es nulo.

Es muy llamativo el hecho de que todas ellas (100\%) se habían casado, y sólo una de ellas se había divorciado después. Pero más sorprendente es el hecho de que la única mujer divorciada había elegido ella misma a su marido. Hecho que resulta muy paradójico, pues podría desprenderse que los mayores (normalmente sus padres) sabían elegir mejor a sus maridos que la propia interesada. De entre ellas, el 70\% pudo elegir marido, y el 30\% había aceptado el hombre que sus padres, mediante casamentera, habían elegido para ellas.

Dado que todas se habían casado, siguiendo la más estricta norma consuetudinaria, también todas ellas habían tenido hijos. El 40\% de ellas había tenido 1 hijo; mientras que había tenido tres el $30 \%$ de ellas. El resto se habían repartido: $10 \%$ de cuatro hijos y el otro 10\%, dos hijos.

Preguntadas por sus maridos, todas ellas (100\%) afirmaron que sus maridos habían sido buenos padres, mientras que esos mismos hombres no necesariamente habían sido buenos maridos. De hecho, respondieron afirmativamente $70 \%$, mientras que un $20 \%$ afirmó que habían sido malos maridos, y el 10\% restante no demasiado malo. La tradición familiar china favorece este comportamiento paterno. Por otra parte, la mujer que afirmó que su marido no había sido buen marido, fue precisamente una de las que lo habían elegido personalmente, y por no ser buena la relación marital, finalmente se había divorciado. 
La respuesta dada al trabajo también resultó muy uniforme dado que el $90 \%$ de las entrevistadas habían trabajado. Sólo el $10 \%$ no lo había hecho, dado que los ingresos eran suficientes como para vivir sin trabajar, cuidando exclusivamente del marido y de los hijos, sin necesidad de hacer aportaciones económicas femeninas.

Igualmente inesperada fue la respuesta referida a la influencia de sus antecesoras femeninas. La mayor parte de ellas $(80 \%)$ sí sentían que sus madres y abuelas habían sido una gran influencia para ellas, y el $20 \%$ restante negaba que lo hubieran sido, porque habían sido pobres e ignorantes (respuesta textual, aproximadamente).

Una de las preguntas centrales, la relativa a sus sueños, arrojó unos resultados también inesperados e interesantes de analizar. El 20\% de ellas sí había tenido sueños y de alguna forma se habían cumplido; mientras que el $50 \%$ afirmó que a pesar de haberlos tenido, se habían quedado muy lejos de haberlos conseguido y de su realidad actual. Mientras, el 30\% restante, no había tenido o no se había permitido tener sueños.

Su realidad era más poderosa que los sueños.

Al final de la entrevista y como conclusión, la mayor parte de ellas afirmó que se sentía satisfecha con su realidad (70\%), mientras que el 30\% restante no lo estaba. Se sentía bastante frustrada y desgraciada, a pesar de que su realidad actual era aceptablemente satisfactoria. Una vez más, la entrevistada que se había divorciado era una de las que no se sentía feliz con su vida, a pesar de que en los otros aspectos tenía una opinión muy similar al resto. Quiere esto decir que la mujer deposita un gran peso de su felicidad sobre sus relaciones afectivoamorosas.

\section{A modo de conclusión}

La primera conclusión, independiente de los resultados, es la gran admiración por estas ancianas fuertes, sensibles y diminutas que han sabido sobrevivir tanto a la hambruna como a la Revolución Cultural sin que ello haya mermado su lucidez o su discernimiento. Ellas supieron soñar sólo hasta el punto en que pudieron darse cuenta de que no se cumplirían. En ese momento, los abandonaron para siempre, para entregarse a su realidad, aceptando la situación que les había tocado vivir.

La subordinación femenina es un hecho universal y pancultural (Bourdieu, 2000). En el caso de las mujeres entrevistadas, han dejado sentir su subordinación y aceptación hacia las ideas y opiniones tanto de sus padres como de sus maridos. En algunos casos, ni siquiera se atrevían a plantearse nada distinto de lo vivido debido a su total aceptación de la realidad y su ciega subordinación mostrada por las decisiones que otros habían tomado por ellas. Entendiendo como "inferior" y "superior" dentro de un sistema de valores aceptado social y naturalmente, esta aparente subordinación e inferioridad es parte de una personalidad pública 
(de cara a la galería) y otra privada (la auténtica y que no se puede manifestar a veces). En sus respuestas sólo se atrevieron a manifestar mediante una expresión no verbalizada, sólo gestual.

Mientras en Europa, según Rivière (2000:9): las mujeres habían encontrado en el siglo $\mathrm{XX}$ su punto de partida, porque en este tiempo habían conseguido, simplemente, ser reconocidas como personas, en China la situación era bien distinta. La tradición cultural china, de una parte, y el régimen político (la transición y la Revolución Cultural) de otro, hizo que las mujeres vivieran un sistema social con ciertas similitudes al sistema medieval europeo.

En China, hombres y mujeres padecen la hambruna y los efectos de la Revolución Cultural. Mientras, en Europa (Rivière, 2000:13): “Amanece una revolución capaz de hacer compatibles la igualdad y la diferencia, de gritar que los seres humanos, hombres o mujeres, no han de ser excluidos o discriminados y de convencer de que las diferencias de raza, sexo, lengua, sensibilidad y cultura son la sal de la vida".

La gran aceptación que las entrevistadas han mostrado hacia su realidad también es extensiva a la conformidad y la aceptación con la que han vivido su propia vida. Mientras que los autores occidentales apuntan prácticamente en su totalidad hacia una desnormalización de las formas sociales existentes, en China, la filosofía, la religión y la conformidad dominante no deja traslucir esta necesidad. Según Celia Amorós (2008:294) quien citando a I.M. Young opina que, "de lo que se trata [...] es de "desnormalizar la forma en que las instituciones formulan sus reglas revelando la circunstancias y necesidades plurales que existen, o que deberían existir en ellas".

Cuando analizaba sus respuestas recordaba también sus expresiones, y lo que a mí me recordó su relato. De hecho, la psicóloga feminista Clarissa Pinkola Estés (2008) relata desde su perspectiva el cuento de Hans Christian Andersen: La Vendedora de fósforos, lo hace para hablar de las posibilidades creativas que tienen unos simple palitos con luz, o dicho de otra forma para ofrecer la posibilidad de crear en las condiciones más desfavorables posibles, y eso es lo que las mujeres chinas conocieron muy bien. Desde su perspectiva junguiana Pinkola hace una interpretación proactiva del cuento y dice literalmente:

"La niña vive en un ambiente de indiferencia. Si tú te encuentras en uno como éste, vete. La niña está en un ambiente en el que no se valora lo que ella tiene, unas llamitas en lo alto de unos palitos, el principio de cualquier posibilidad creativa. Si tú te encuentras en este apuro, da la media vuelta y aléjate" (Pinkola, 2008:345).

En el caso de la niña, ésta muestra un instinto de supervivencia, a pesar de la ausencia del ambiente necesario. No intenta demostrar nada, sólo sobrevivir. Como para esta vendedora de cerillas, las mujeres chinas entrevistadas sólo intentaban sobrevivir y salvar a sus hijos. La manifestación final de conformidad con la vida venía ratificada por el hecho de que habían podido comer y dar de comer a sus hijos, así como ofrecerles una educación y una vida mejor que la de ellas mismas.

La secular y patriarcal tradición china ha favorecido que las mujeres acepten su subordinación como algo natural, al igual que su aceptación por la vida en general, tal como les 
ha sido dada. Estas mujeres, que sufrieron y superaron la transición política más fuerte del continente asiático (La Revolución Cultural) con su esfuerzo, aceptación y resignación, han dado paso a una generación de mujeres mucho más fuertes, independientes, determinadas y emprendedoras, lo que demuestra que como dijeron Castells y Subirats (2004:46); "El patriarcado es un sistema de dominación de profunda raigambre histórica pero no es inamovible ni eterno". De hecho, China es un país emergente en todos los ámbitos, no sólo en el económico.

La globalización actual ha unificado en gran medida las formas de pensar, de modo que mujeres chinas y españolas son más similares que lo fueron en generaciones pasadas. Como dijo Rivière (2000:247): "Ser un hombre o una mujer son formas de estar en el mundo y de cada cual dependerá que resulte provechoso. Pero es tarea de todos que los individuos logren ser personas y eso sólo puede producirse en un entorno acogedor, no agobiante, no sobreprotegido, no aislado, no temeroso". En este sentido, hombres y mujeres son conscientes de que un mundo mejor sólo es posible con dos tipos de actores distintos: hombres y mujeres, pero con iguales derechos y obligaciones.

El destilado de sus entrevistas induce a pensar que a pesar de las diferencias culturales, mujeres orientales y occidentales, es decir chinas y españolas, no han sido o no son tan distintas. Esta relación comparativa podría plantearse para una próxima investigación que permitiera afirmar tal inferencia, cosa que no se descarta, sino más bien al contrario, se mira con mucho interés.

\section{Agradecimientos}

El artículo nunca hubiera sido posible sin la colaboración de distintas personas y entidades. Por ello, quiero mostrar mi agradecimiento: para la traducción e interpretación) Xiu Lu, traductora literaria de chino-español, traductora de la obra de Dulce Chacón para Alfaguara, que no sólo interpretó sino también facilitó dos entrevistadas; para la realización y transcripción de varias entrevistas, Roberto H. E. OEST, profesor especializado en japonés y chino y algunos de sus estudiantes; para la localización de entrevistadas, el profesor A. Lucas; por las recomendaciones e información a las instituciones españolas: Agregaduría Cultural de la Embajada, dirigida por Carmen Moreno; y el Instituto Cervantes, dirigido por Inmaculada González, en aquel momento. 


\section{BibLiOgRAFÍA}

- Aguado, Ana María et al. (1994): Textos para la historia de las mujeres en España. Madrid: Cátedra.

- Amorós, Celia (2008): Tiempo de feminismo. Sobre feminismo, proyecto ilustrado y postmodernidad. Madrid: Cátedra.

- Bourdieu, Paul (2000): La dominación masculina. Barcelona: Anagrama.

- Castells, Manuel y Subirats, Marina (2004): Mujeres y hombres. ¿Un amor imposible?. Madrid: Alianza.

- Castilla del Pino, Carlos (1971): Cuatro ensayos sobre la mujer. Madrid: Alianza.

- Chang, Jung (2004): Cisnes salvajes. Tres hijas de China. Barcelona: Circe.

- Duby, Georges (1992): El amor en la Edad Media y otros ensayos, Madrid: Alianza. Título original: Mâle Moyen Age. De l'amour et autres essais. Traducción: Ricardo Artola.

- García Gual, Carlos (2001): Edición de Epicuro: Sobre el placer y la felicidad. Barcelona: Círculo de Lectores.

- Gómez y Patiño, María (2010): "Repensar la identidad femenina". En: Cuestiones de género: de la igualdad y la diferencia, $\mathrm{n}^{\circ}$ 5. León: Servicio de Publicaciones de la Universidad de León, pp. 541-562.

- Marquard, Odo (2006): Felicidad en la infelicidad. Reflexiones filosóficas. Buenos Aires: Katz Editores.

- Martínez, Cándida (1994): Introducción. En: Ana María Aguado et al.: Textos para la historia de las mujeres en España. Madrid: Cátedra. pp. 29-39.

- Mead, Margaret (1994): Experiencias personales y científicas de una antropóloga, Barcelona: Paidós.

- Pardo, José Luis (2002): Prólogo a Schopenhauer: El arte de saber vivir. Barcelona: Círculo de Lectores, pp. 7-23.

- Pinkola Estés, Clarissa (2008): Mujeres que corren con los lobos. Barcelona: Ediciones B.

- Rivière, Margarita (2000): El mundo según las mujeres, Barcelona: Círculo de Lectores.

- Schopenhauer, Arthur (2002): El arte de saber vivir, Círculo de Lectores: Barcelona.

- Siu, Ralfph Gunn H. (1968): The Man of many qualities. Cambridge: Mass.

- Todorov, Tzvetan (2010): Nosotros y los otros. Reflexión sobre la diversidad humana, Madrid: Siglo XXI. 